\title{
Assessment of the embryotoxicity of four Chinese herbal extracts using the embryonic stem cell test
}

\author{
LIN-YAN LI $^{1 *}$, FEN-FANG CAO ${ }^{1 *}$, ZHI-JIAN SU ${ }^{2}$, QI-HAO ZHANG ${ }^{2}$, XIAO-YONG DAI ${ }^{1}$, \\ $\mathrm{XUE} \mathrm{XIAO}^{2}$, YA-DONG HUANG ${ }^{2}$, QING ZHENG ${ }^{1}$ and HUA XU ${ }^{1}$ \\ ${ }^{1}$ Department of Microbiological and Biochemical Pharmacy, College of Pharmacy, Jinan University; \\ ${ }^{2}$ Department of Biopharmaceutical Research and Development Centre, Jinan University, \\ Guangzhou, Guangdong 510632, P.R. China
}

Received February 20, 2014; Accepted November 7, 2014

DOI: $10.3892 / \mathrm{mmr} .2015 .3598$

\begin{abstract}
Rhizoma Atractylodes macrocephala, Radix Isatidis, Coptis chinensis and Flos Genkwa are common herbal remedies used by pregnant woman in China. In this study, their potential embryotoxicity was assessed using the embryonic stem cell test (EST) and a prediction model. The potential embryotoxicity of the herbs was based on three endpoints: the concentrations of the compounds that inhibited the proliferation of $50 \%$ of embryonic stem cells (ESCs) $\left(\mathrm{IC}_{50} \mathrm{ES}\right)$, the concentrations that inhibited $50 \%$ of $3 \mathrm{~T} 3$ cells $\left(\mathrm{IC}_{50} 3 \mathrm{~T} 3\right)$, and the concentrations that inhibited the differentiation of $50 \%$ of ESCs $\left(\mathrm{ID}_{50} \mathrm{ES}\right)$. The results revealed that Rhizoma Atractylodes macrocephala and Radix Isatidis are non-embryotoxic compounds. Coptis chinensis extracts appeared to demonstrated weak embryotoxicity, and Flos Genkwa exhibited strong embryotoxicity. These results may be useful in guiding the clinical use of these herbs and in expanding the application of the EST to the field of traditional Chinese medicine.
\end{abstract}

\section{Introduction}

Chinese medicine has played an invaluable role in the prevention and treatment of diseases for thousands of years in China. Although Chinese medicine was considered to have less toxicity and fewer side effects than traditional medicine, increasing evidence has shown this to be untrue (1-3). Given that many pregnant women use Chinese herbs for pregnancy-related

Correspondence to: Professor Qing Zheng or Professor Hua Xu, Department of Microbiological and Biochemical Pharmacy, College of Pharmacy, Jinan University, 601 Huangpu Venue West, Tianhe, Guangzhou, Guangdong 510632, P.R. China

E-mail: tzhengq@jnu.edu.cn

E-mail: huax_mail@126.com

${ }^{*}$ Contributed equally

Key words: traditional Chinese medicine, embryotoxicity, embryonic stem cell test sickness $(4,5)$, the potential developmental toxicity of these herbs needs to be studied. In the present study, we investigated the safety and possible embryonic toxicity of four common herbs: Rhizoma Atractylodes macrocephala, Radix Isatidis, Coptis chinensis and Flos Genkwa.

Atractylodes macrocephala has been used in traditional Chinese medicine (TCM) for approximately 2,000 years. It exhibits multipharmacological effects and is used to treat various complaints, including excessive vaginal bleeding (6). It is also used to invigorate the spleen (7). As a typical Chinese herbal medicine for replenishing qi, Rhizoma Atractylodes macrocephala has long been used in the treatment of threatened preterm labor.

Radix Isatidis is the dried root of crucifer Isatis tinctoria L, which is widely distributed in northern and central China. According to a book on herbal medicine written in 110 B.C. by Shennong, a notable ancient Chinese medicinal specialist, it has been used as a medicinal plant for more than 2,000 years. It is used to dissipate heat (cold compress), detoxify the immune system and cool the blood. It is widely used for preventing and treating infectious diseases caused by viruses, including influenza, viral pneumonia, mumps and hepatitis (8).

The use of Coptis chinensis as a herbal remedy was also first recorded in Shennong's book. This herb is used to dissipate heat and promote diuresis. It is used as a common herbal medicine for diarrhea, dysentery, acute febrile and suppurative infections and vomiting, as well as to protect the gastric mucosa (9). Coptis chinensis has been used for thousands of years in China. However, it has been banned in Singapore since 1978 due to the belief that taking this herb during pregnancy or lactation causes serious jaundice in infants.

Flos Genkwa, the dried flower buds of Daphne genkwa, is a medicinal plant distributed mainly in mainland China. It is commonly used as an abortifacient (10), with purgative, diuretic and anti-inflammatory actions (11). Since the enactment of China's one-child family planning policy, studies of Flos Genkwa have focused on its abortion efficacy and mechanisms (12). One previous study has investigated its anticancer actions (13).

A systematic study of the use of Chinese herbal medicines during pregnancy has not been conducted. Currently, teratogenicity tests in vivo or genetic toxicity tests are the main methods 
employed to study the reproductive and developmental toxicity of TCM $(14,15)$. Whole embryo cultures or micromass embryo cell cultures have also been used to reveal the developmental toxicity of TCM (16). Comparatively speaking, in vivo tests, based on maternal or embryonic exposure of laboratory animals, are more time-consuming and expensive. In vitro assays, including the whole-embryo culture assay and the micromass assay, offer an alternative to in vivo assessment, although both still rely on embryos (17). Spielmann and Liebsch developed the embryonic stem cell test (EST), an in vitro assay system to determine the teratogenic potential of test chemicals (18). It is the only test not requiring pregnant animals (19). The EST is based on murine-derived embryonic stem cells (ESCs) from the blastocyst stage. ESCs are pluripotent cells. They differentiate in vitro into a wide variety of cell types, representing all three germ layers (ectoderm, mesoderm and endoderm). Under appropriate culture conditions, certain ESCs differentiate spontaneously into beating myocard cells. Three different endpoints are evaluated in the EST: The inhibition of growth (cytotoxicity) of $3 \mathrm{~T} 3$ cells and ESCs after 10 days of treatment, determined by the Cell Counting Kit-8 (CCK8) cell proliferation assay, and the inhibition of the differentiation of ESCs into myoblasts following 10 days of treatment. The concentration \pm response correlations are recorded, and 50\% inhibition concentrations are determined for the three endpoints. In the EST, the mutagenic potential of the test substances are classified into three different classes of in vivo embryotoxic potencies: strongly embryotoxic, weakly embryotoxic and non-embryotoxic (20). In a previous study, the EST was used to verify the embryotoxicity of 20 reference compounds with the different embryotoxic potencies mentioned above. The accuracy of the EST assay was $78 \%$. Notably, a predictivity of $100 \%$ was attained for strong embryotoxicants (21). As a result, the validated EST has been accepted for assessing the embryotoxicity of test compounds at an early stage of development (22). However, there are few reports on the application of the EST to the study of the reproductive and developmental toxicity of TCM $(23,24)$.

The aim of the present study was to evaluate the embryonic developmental toxicity of extracts of four TCMs (Rhizoma Atractylodes macrocephala, Radix Isatidis, Coptis chinensis and Flos Genkwa). For this purpose, a modified EST was used. Three endpoints $\left(\mathrm{IC}_{50} 3 \mathrm{~T} 3, \mathrm{IC}_{50} \mathrm{ES}\right.$ and $\left.\mathrm{ID}_{50} \mathrm{ES}\right)$ were used for each extract, and each test compound was classified as strongly, weakly or non-embryotoxic.

\section{Materials and methods}

Preparation of crude drug extracts. Roots of Atractylodesmacrocephala, Coptis chinensis, Radix Isatidis and Flos Genkwa were purchased from Caizhiling, a reputable Chinese medicinal herb store in Guangzhou, China. Their authenticity was confirmed by Professor Ma Zhiguo of the Pharmacy College of Jinan University. The aqueous extract was prepared by a general method. After cutting the herbs into small pieces, $100 \mathrm{~g}$ dried plant material was boiled in 1,000 $\mathrm{ml}$ distilled water for $1 \mathrm{~h}$. The decoction was collected and the residue was boiled another two times. The decoction obtained from the three separated extractions was mixed, filtered and lyophilized by freeze drying. The powdered forms of the extracts were stored at $-20^{\circ} \mathrm{C}$.
Preparation of extracts and pure compound solutions. The dried extracts were dissolved in double-distilled water until the initial concentration was $1 \mathrm{~g} / \mathrm{ml}$ and centrifuged at $14,000 \mathrm{~g}$ for $5 \mathrm{~min}$ before filtration sterilization to obtain a clear, sterile supernatant for testing. The chemicals were dissolved in appropriate solvents. The chemical 5-fluorouracil (5-FU; Sigma-Aldrich, St. Louis, MO, USA) was dissolved in dimethylsulphoxide. Phenytoinum natricum (DPH; Sigma-Aldrich) and saccharin (SAC; Sigma-Aldrich) were dissolved in phosphate-buffered saline (PBS). The final solvent concentrations applied in the differentiation and cytotoxicity assays demonstrated no undesired background effects.

Cell culture. Undifferentiated mouse ESCs of the $\mathrm{OG}_{2}$ cell line were purchased from the Chinese Academy of Sciences. Continuous cultures of the cell line were grown on mitomycin $\mathrm{C}$ inactivated mouse embryonic fibroblast (MEF) feeders in a standard culture medium consisting of $80 \%$ high-glucose (4.5 g glucose/1) Dulbecco's modified Eagle's medium (DMEM; Gibco Life Technologies, Karlsruhe, Germany), $15 \%$ fetal calf serum (Hyclone, Erembodegem-Aalst, Belgium), as well as $2 \mathrm{mM}$ glutamine, $2 \mathrm{mM}$ sodium pyruvate, antibiotics (50 U/ml penicillin and $50 \mu \mathrm{g} / \mathrm{ml}$ streptomycin), $1 \%$ non-essential amino acids, $0.1 \mathrm{mM} \beta$-mercaptoethanol and $1,000 \mathrm{U} / \mathrm{ml}$ murine leukemia inhibitory factor, which were all purchased from Gibco Life Technologies. BALB/c 3T3 fibroblasts, purchased from the cell bank of Sun Yat-sen University of Medical Sciences, were cultured in DMEM supplemented with $10 \%$ fetal calf serum, $50 \mathrm{U} / \mathrm{ml}$ penicillin and $50 \mu \mathrm{g} / \mathrm{ml}$ streptomycin. The cells were maintained under $5 \% \mathrm{CO}_{2}$ and $95 \%$ humidity at $37^{\circ} \mathrm{C}$.

Alkaline phosphatase staining. The ESCs were subjected to alkaline phosphatase (AKP) staining on day 5 of passage. The original medium was discarded from the culture plates, and the cells were washed with PBS and fixed in $4 \%$ paraformaldehyde for $10 \mathrm{~min}$. They were then washed again with PBS and stained with $75 \mathrm{mg} / \mathrm{ml}$ nitrotetrazolium blue chloride (Inogent, Hyderabad, India) and $50 \mathrm{mg} / \mathrm{ml}$ 5-bromo-4-chloro-3-indolylphosphate (Innogent) for $1 \mathrm{~h}$ at room temperature.

Cytotoxicity assay. The cytotoxic effects on the mESCs and $3 \mathrm{~T} 3$ cells were detected by performing a CCK8 (Mbchem, Mumbai, India) cell proliferation assay on day 10 . In brief, on day 1, 500 cells were seeded into each well of a 96-well tissue plate in a routine cell culture medium without leukemia inhibitory factor and incubated for $2 \mathrm{~h}$. Following incubation, $200 \mu \mathrm{l}$ culture medium containing the appropriate dilution of extracts from the four medicines were added to each well. On days 3 and 5 , the medium was renewed. On day 10, CCK8 assay was carried out. Cytotoxicity was expressed as the concentration of the compound that reduced the viability of cells to $50 \%$ of the control level $\left(\mathrm{IC}_{50} 3 \mathrm{~T} 3\right.$ and $\left.\mathrm{IC}_{50} \mathrm{ES}\right)$, determined from a concentration-response curve.

Differentiation assay. Differentiation assays were performed to detect compound-induced changes in the differentiation of the mESCs into contracting cardiomyocytes. Briefly, on day 0 , $20 \mu \mathrm{l}$ stem cell suspension containing 750 cells was placed as 
hanging drops on the inner side of the lid of a petri dish filled with $6 \mathrm{ml} \mathrm{PBS}$, then incubated for three days at $37^{\circ} \mathrm{C}$, with $5 \%$ $\mathrm{CO}_{2}$ and $95 \%$ humidity, in the presence of the test chemicals at various concentrations. During this period, the cells formed aggregates referred to as embryonic bodies (EBs). After three days, the aggregates that formed were transferred to bacterial petri dishes and exposed to the appropriate concentration of the test chemical for another two days. On day 5, the EBs were placed individually into six wells of a Falcon tissue culture plate. On day 10, the EBs were collected for quantitative polymerase chain reaction (qPCR) detection to observe the expression of related genes.

$q P C R$. The cell samples for analysis were collected on day 10 of the differentiation assay, and total RNA was extracted using an EZNA ${ }^{\mathrm{TM}}$ Total RNA kit II (Omega Bio-Tek, Norcross, GA, USA) according to the instructions of the manufacturer. cDNA was synthesized using $1 \mu \mathrm{g}$ RNA and PrimeScript ${ }^{\mathrm{TM}}$ RT Master mix (Takara, Otsu, Japan) as per the instructions of the manufacturer. The reaction mixture was incubated at $37^{\circ} \mathrm{C}$ for $30 \mathrm{~min}$, followed by $5 \mathrm{sec}$ at $85^{\circ} \mathrm{C}$. To verify the undifferentiated marker genes Sox 2 and Oct 4 and the myocardial-specific marker $\beta$-myosin heavy chain ( $\beta$-MHC), qPCR was performed using SsoAdvanced ${ }^{\mathrm{TM}}$ SYBR-Green (Bio-Rad Laboratories, Hercules, CA, USA). qPCR reactions were conducted in a 20- $\mu \mathrm{l}$ mixture that included $10 \mu \mathrm{l} 2 \mathrm{X}$ qPCR Master mix, $8 \mu \mathrm{l}$ nuclease-free water with mouse-specific primers for glyceraldehyde-3-phosphate dehydrogenase (GAPDH; 5'-GCCTTC TCCATGGTGGTGAA-3' and 5'-GCACAGTCAAGGCCGA GAAT-3') and $\beta$-MHC (5'-TCCGCAACCGAGAGAATCAG-3' and 5'-TGTCGCCAGAAATTGTGCCTT-3'), and $2 \mu \mathrm{l}$ cDNA template. The thermal cycle profile consisted of an initial 30 -min step at $95^{\circ} \mathrm{C}$, followed by 40 cycles of $95^{\circ} \mathrm{C}$ for $5 \mathrm{sec}$, and $60^{\circ} \mathrm{C}$ for $20 \mathrm{~min}$. The CFX Connect Real-Time system and CFX Manager Software (version 2.0; Bio-Rad) were used to collect the PCR data. The RNA levels of each gene were normalized to GAPDH.

Classification of the embryotoxic potential of the four extracts. Two permanent mouse cell lines of ESCs and 3T3 cells were used to predict the cytotoxicity of the test compounds using the EST. The concentrations of the compounds that inhibited the proliferation of $50 \%$ of the ESCs and $50 \%$ of the $3 \mathrm{~T} 3$ cells $\left(\mathrm{IC}_{50} \mathrm{ES}\right.$ and $\left.\mathrm{IC}_{50} 3 \mathrm{~T} 3\right)$ were determined with CCK8 assay. In addition, the concentration that inhibited the differentiation of $50 \%$ of the ESCs $\left(\mathrm{ID}_{50} \mathrm{ES}\right)$ was obtained from the results of qPCR in a differentiation assay. The three endpoints obtained in each experiment were used to calculate linear discriminant functions (I, II, III) for each extract.

I. $5.9157 \mathrm{lg}\left(\mathrm{IC}_{50} 3 \mathrm{~T} 3\right)+3.500 \mathrm{lg}\left(\mathrm{IC}_{50} \mathrm{ES}\right)-5.307$ $\left(\mathrm{IC}_{50} 3 \mathrm{~T} 3-\mathrm{ID}_{50} \mathrm{ES}\right) / \mathrm{IC}_{50} 3 \mathrm{~T} 3-15.72$;

II. $3.6511 \mathrm{lg}\left(\mathrm{IC}_{50} 3 \mathrm{~T} 3\right)+2.3941 \mathrm{lg}\left(\mathrm{IC}_{50} \mathrm{ES}\right)-2.033$ $\left(\mathrm{IC}_{50} 3 \mathrm{~T} 3-\mathrm{ID}_{50} \mathrm{ES}\right) / \mathrm{IC}_{50} 3 \mathrm{~T} 3-6.85$;

III. $-0.125 \mathrm{lg}\left(\mathrm{IC}_{50} 3 \mathrm{~T} 3\right)+1.917 \mathrm{lg}\left(\mathrm{IC}_{50} \mathrm{ES}\right)+1.500$ $\left(\mathrm{IC}_{50} 3 \mathrm{~T} 3-\mathrm{ID}_{50} \mathrm{ES}\right) / \mathrm{IC}_{50} 3 \mathrm{~T} 3-2.67$.

Depending on the variables of the three functions I, II and III, the embryotoxicity of a test compound can be classed as non-embryotoxic (Class 1), weakly embryotoxic (Class 2) or strongly embryotoxic (Class 3).

The classification criteria were as follows: Class 1: if I $>$ II and I $>$ III; Class 2: if II >I and II $>$ III; and Class 3: if III $>$ I and III $>$ II.

We first used a modified EST to determine the effect of 5-FU, DPH and SAC on differentiation and to classify the embryotoxic potential of each compound, which was revealed to be strong, weak and non-existent, respectively, to verify the predictive validity of the EST we established. Subsequently, the embryotoxic classification of the four herbal extracts was determined with the modified EST.

Statistical analysis. The statistical analysis was performed using GraphPad Prism 5 (GraphPad Prism Software, Inc., San Diego, CA, USA). Each data point represented three independent experiments. Data are given as the mean \pm SEM. A one-way ANOVA was used to assess the statistical significance. $\mathrm{P}<0.05$ was considered to indicate a statistically significant difference.

\section{Results}

Verification of the undifferentiated ESCs. We verified the undifferentiated cells through morphology, AKP staining and qPCR to determine the expression levels of undifferentiated markers in undifferentiated cells. Observed under the microscope, the ESCs were nest-like, compact clones, with clear boundaries (Fig. 1A). They were AKP-positive and deep brown in color (Fig. 1B). The expression levels of the undifferentiated markers Sox2, Oct4 and Nanog were much higher than in the negative control, MEF (Fig. 1C). These results indicated that the ESCs were undifferentiated, and they were used in subsequent experiments.

Validity check of EST. The modified EST model was verified by determining the embryotoxicity of 5-FU (Fig. 2), DPH (Fig. 3) and SAC (Fig. 4). Three endpoint values were obtained for each compound. Detailed data on the endpoint values are shown in Table I. We confirmed that 5-FU had strong embryotoxicity, DPH was weakly embryotoxic and SAC was non-embryotoxic.

Embryotoxicity of four TCM extracts. The four TCMs (Rhizoma Atractylodes macrocephala, Radix Isatidis, Coptis chinensis and Flos Genkwa) were decocted with water, and the EST was performed to determine the embryotoxic potential of the extracts. Three endpoints were obtained for each extract from three independent experiments. The cytotoxicity of the extracts on the $\mathrm{OG}_{2}$ cells and the $3 \mathrm{~T} 3$ cells $\left(\mathrm{IC}_{50} 3 \mathrm{~T} 3\right.$ and $\left.\mathrm{IC}_{50} \mathrm{ES}\right)$ was determined with a CCK8 assay, and the inhibition of cardiomyocyte differentiation of the ESCs ( $\mathrm{ID}_{50} \mathrm{ES}$; based on the expression levels of the $\beta$-MHC gene) was determined by qPCR. The three parameters of each extract were substituted into three linear discriminant functions (I, II and III). Detailed data on the classification of the embryotoxic potential of each extract using the criteria for embryotoxicity are provided in Table I.

Rhizoma Atractylodes macrocephala. In the cytotoxicity assay, the $\mathrm{IC}_{50} 3 \mathrm{~T} 3$ value was $4.82 \mathrm{mg} / \mathrm{ml}$, which was $\sim 1 / 10$ 
Table I. Three endpoint values of test compounds in the embryonic stem cell test.

\begin{tabular}{|c|c|c|c|c|c|c|c|c|}
\hline Test & $\mathrm{IC}_{50} 3 \mathrm{~T} 3$ & $\mathrm{IC}_{50} \mathrm{ES}$ & $\mathrm{ID}_{50} \mathrm{ES}$ & I & II & III & Criteria & Classification \\
\hline SAC & 2790.00 & 3009.00 & 2156.00 & 15.63 & 13.60 & -9.43 & $\mathrm{I}>\mathrm{II}$ and $\mathrm{I}>\mathrm{III}$ & 1 \\
\hline DPH & 89.76 & 67.87 & 14.13 & -2.23 & 2.95 & -5.16 & II $>$ I and II $>$ III & 2 \\
\hline $5-\mathrm{FU}$ & 0.25 & 0.05 & 0.07 & -27.79 & -13.72 & 1.05 & III $>$ I and III $>$ II & 3 \\
\hline Atractylodes & 4.82 & 42.42 & 37.67 & 30.19 & 13.40 & -16.10 & $\mathrm{I}>\mathrm{II}$ and $\mathrm{I}>\mathrm{III}$ & 1 \\
\hline R. Isatidis & 1.76 & 27.68 & 15.00 & 30.00 & 12.79 & -16.74 & $\mathrm{I}>\mathrm{II}$ and $\mathrm{I}>\mathrm{III}$ & 1 \\
\hline C. chinensis & 0.40 & 2.73 & 1.06 & -7.73 & -3.89 & -5.95 & II $>$ I and II $>$ III & 2 \\
\hline Flos Genkwa & 0.51 & 0.75 & 1.15 & -11.18 & -5.65 & -4.77 & III $>$ I and III $>$ II & 3 \\
\hline
\end{tabular}

Sac, saccharine; DPH, phenytoinum natricum; 5-FU, 5-fluorouracil; Atractylodes, Rhizoma Atractylodes macrocephala; R. Isatidis, Radix Isatidis; C. chinensis, Coptis chinensis.
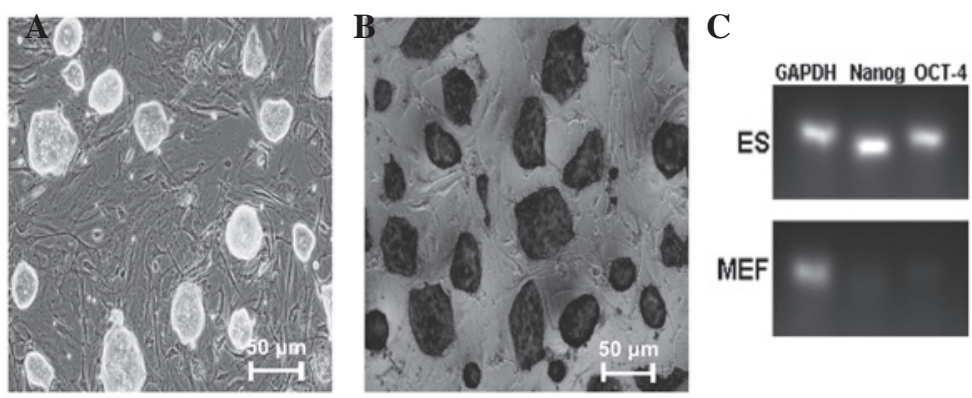

Figure 1. Detection of undifferentiated state of embryonic stem cells (ESCs). (A) Mouse embryonic stem cell growth in the feeder layer (magnification, x100); (B) Alkaline phosphatase staining of ESCs (magnification, x100); (C) Expression of undifferentiated Oct4 and Nanog genes of ESCs. MEF, mouse embryonic fibroblast; GAPDH, glyceraldehyde-3-phosphate dehydrogenase.
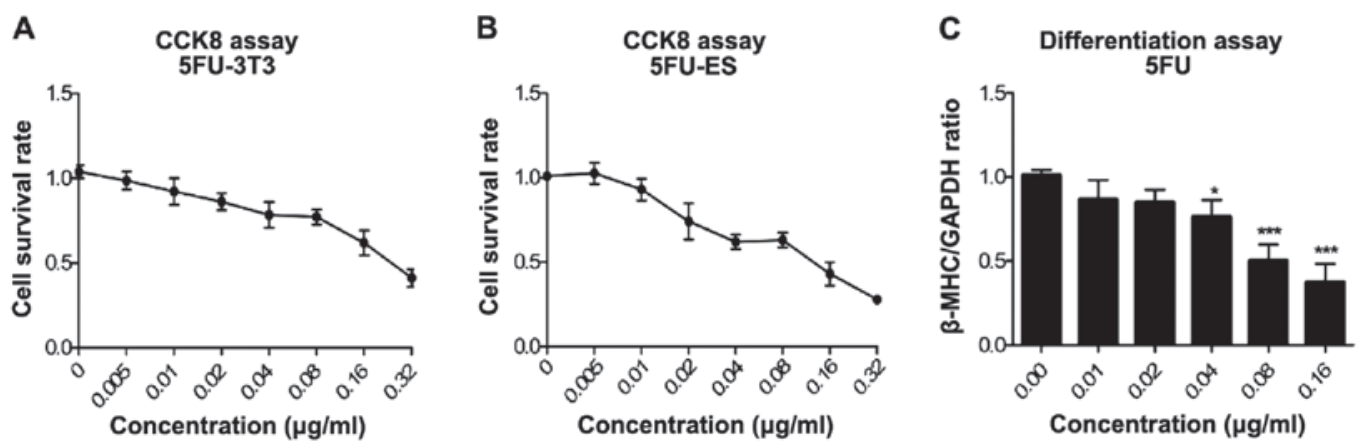

Figure 2. Embryonic stem cell (ESC) test for 5-fluorouracil (5-FU). Cytotoxicity assay with 3T3 cells (A) and ESCs (B). Differentiation ESC assay (C). Relative levels of $\beta$-myosin heavy chain expression and cytotoxicity are represented as a percentage of the solvent control (control=100\%). Values are means \pm SEM $(\mathrm{n}=3) .{ }^{*} \mathrm{P}<0.05,{ }^{* *} \mathrm{P}<0.01,{ }^{* * *} \mathrm{P}<0.001$.

A

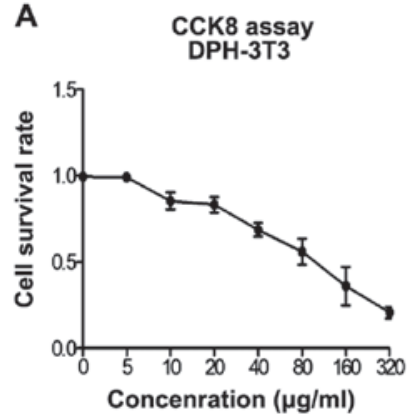

B

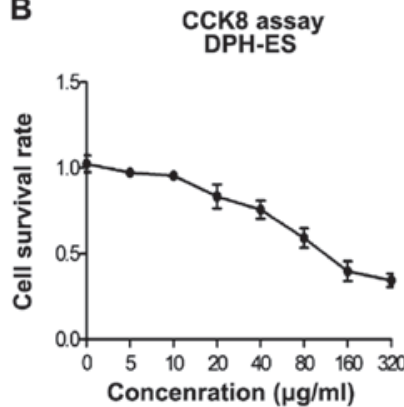

C Differentiation assay

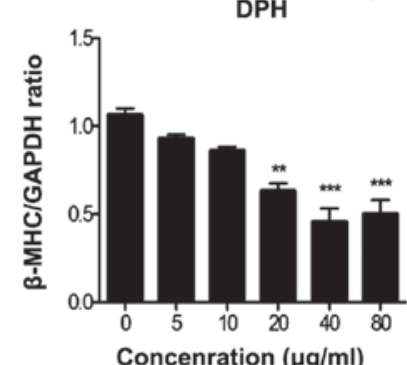

Figure 3. Embryonic stem cell (ESC) test for phenytoinum natricum (DPH). Cytotoxicity assay with 3T3 cells (A) and ESCs (B). Differentiation ESC assay (C). Relative levels of $\beta$-myosin heavy chain expression and cytotoxicity are represented as a percentage of the solvent control (control=100\%). Values are means \pm SEM $(\mathrm{n}=3) .{ }^{*} \mathrm{P}<0.05,{ }^{* * *} \mathrm{P}<0.01,{ }^{* * *} \mathrm{P}<0.001$. 

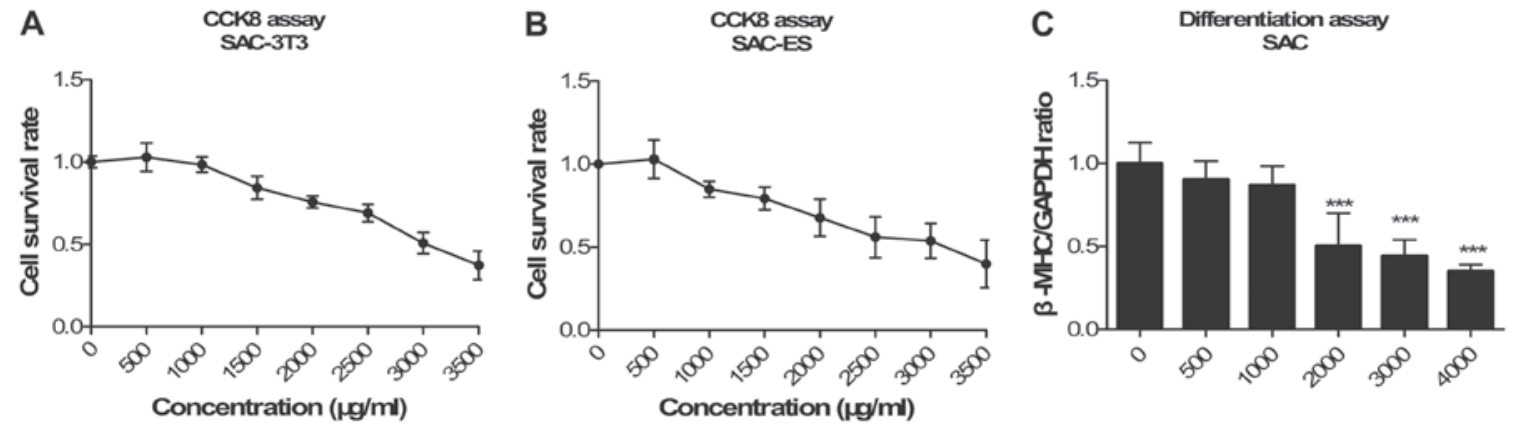

Figure 4. Embryonic stem cell (ESC) test for saccharin (SAC). Cytotoxicity assay with 3 T3 cells (A) and ESCs (B). Differentiation ESC assay (C). Relative levels of $\beta$-myosin heavy chain expression and cytotoxicity are represented as a percentage of the solvent control (control=100\%). Values are means \pm SEM $(\mathrm{n}=3) .{ }^{*} \mathrm{P}<0.05,{ }^{* * *} \mathrm{P}<0.01,{ }^{* * * *} \mathrm{P}<0.001$.

A

Rhizoma Atractylodis Macrocephala-3T3

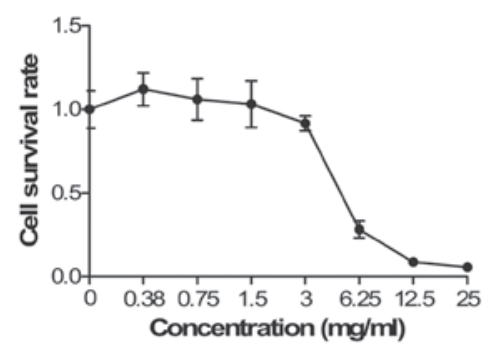

B

CCK8 assay

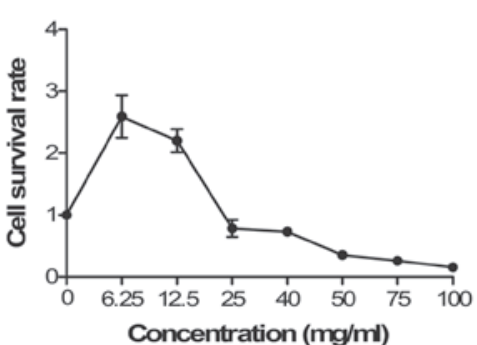

Differentiation assay Rhizoma Atractylodis Macrocephala

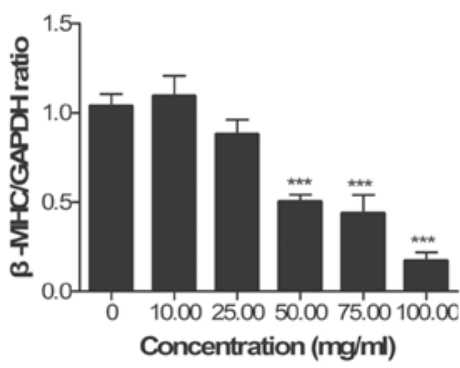

Figure 5. Embryonic stem cell (ESC) test for Rhizoma Atractylodis macrocephala. Cytotoxicity assay with 3T3 cells (A) and ESCs (B). Differentiation ESC assay (C). Relative levels of $\beta$-myosin heavy chain expression and cytotoxicity are represented as a percentage of the solvent control (control=100\%). Values are means $\pm \operatorname{SEM}(\mathrm{n}=3) .{ }^{*} \mathrm{P}<0.05,{ }^{* *} \mathrm{P}<0.01,{ }^{* * *} \mathrm{P}<0.001$.
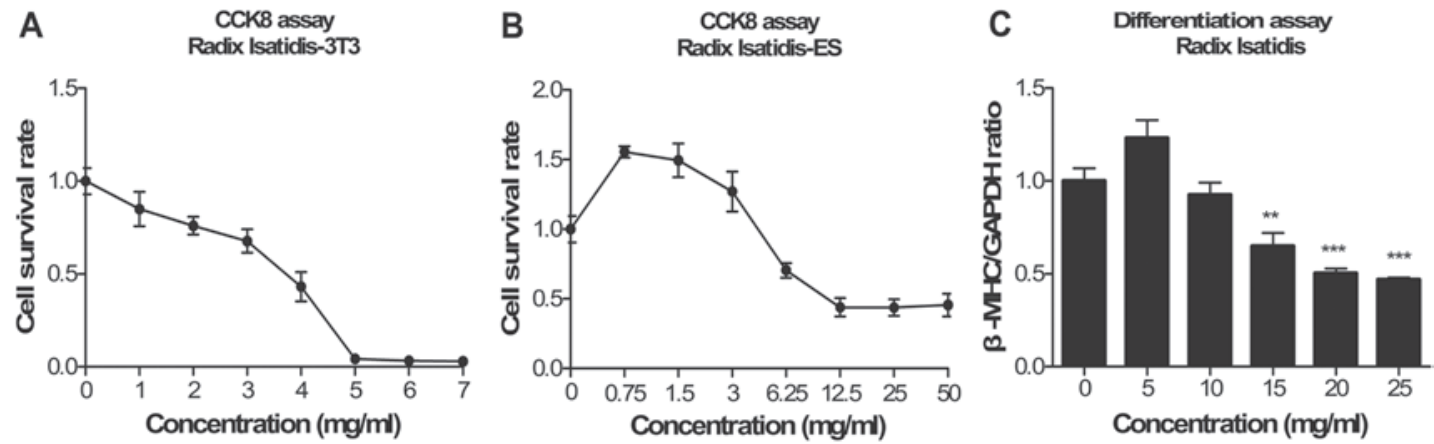

Figure 6. Embryonic stem cell (ESC) test for Radix Isatidis. Cytotoxicity assay with 3T3 cells (A) and ESCs (B). Differentiation ESC assay (C). Relative levels of $\beta$-myosin heavy chain expression and cytotoxicity are represented as a percentage of the solvent control $($ control=100\%). Values are means \pm SEM ( $=3)$. ${ }^{*} \mathrm{P}<0.05,{ }^{* *} \mathrm{P}<0.01,{ }^{* * *} \mathrm{P}<0.001$.

that of the $\mathrm{IC}_{50} \mathrm{ES}$ value $(42.42 \mathrm{mg} / \mathrm{ml}$; Fig. $5 \mathrm{~A}$ and $\mathrm{B})$. The $\mathrm{ID}_{50}$ value for Rhizoma Atractylodes macrocephala was $37.67 \mathrm{mg} / \mathrm{ml}$ (Fig. 5C). It promoted the survival of ESCs and led to cardiac differentiation of ESCs at a low concentration. Thus, it was defined as a non-embryotoxic compound.

Radix Isatidis. ESCs increased at a low Radix Isatidis concentration. As the concentration increased, the survival rate of the ESCs declined. The proliferation of the 3T3 cells was suppressed at a low concentration, whereas the proliferation of the ESCs was promoted (Fig. 6A and B). The $\mathrm{IC}_{50}$ values were 1.76 and $27.68 \mathrm{mg} / \mathrm{ml}$ for the $3 \mathrm{~T} 3$ fibroblasts and the ESCs, respectively. The expression levels of $\beta$-MHC decreased in a concentration-dependent manner following exposure to Radix Isatidis extract (Fig. 6C). The ID $_{50}$ values were $15 \mathrm{mg} / \mathrm{ml}$. Radix Isatidis extract was classified as non-embryotoxic.

Coptis chinensis. In both cell lines, the Coptis chinensis extract inhibited the survival of cells in a dose-dependent manner (Fig. 7A and B). The cytotoxic sensitivity of the 3T3 fibroblasts was much higher than that of the ESCs exposed to Coptis chinensis extract. The $\mathrm{IC}_{50}$ values were 0.398 and $2.73 \mathrm{mg} / \mathrm{ml}$ for the $3 \mathrm{~T} 3$ fibroblasts and the ESCs, respectively. 

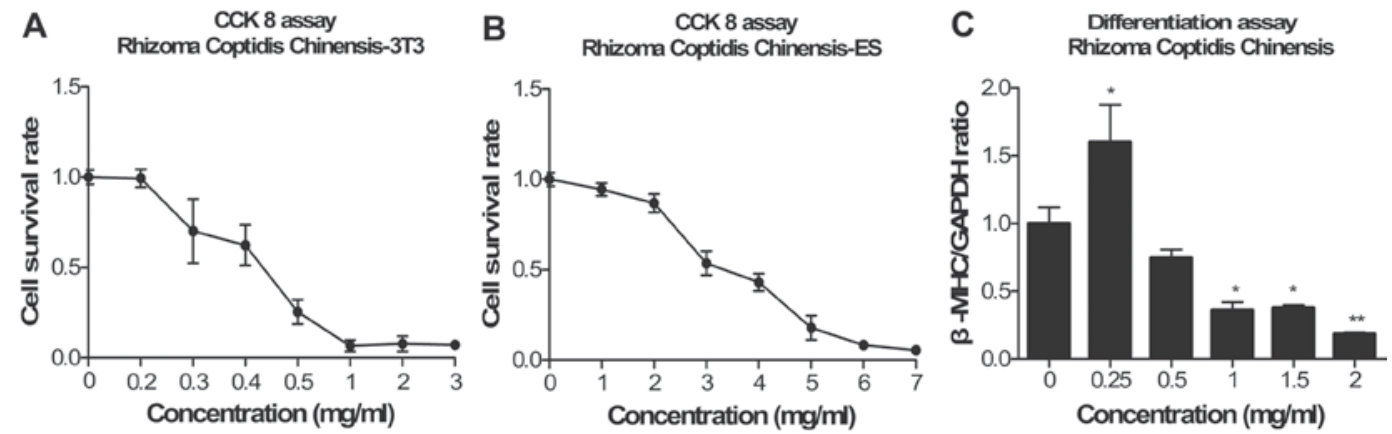

Figure 7. Embryonic stem cell (ESC) test for Coptis chinensis. Cytotoxicity assay with 3 T3 cells (A) and ESCs (B). Differentiation ESC assay (C). Relative levels of $\beta$-myosin heavy chain expression and cytotoxicity are represented as a percentage of the solvent control (control=100\%). Values are means \pm SEM $(\mathrm{n}=3) .{ }^{*} \mathrm{P}<0.05,{ }^{* * *} \mathrm{P}<0.01,{ }^{* * * *} \mathrm{P}<0.001$.
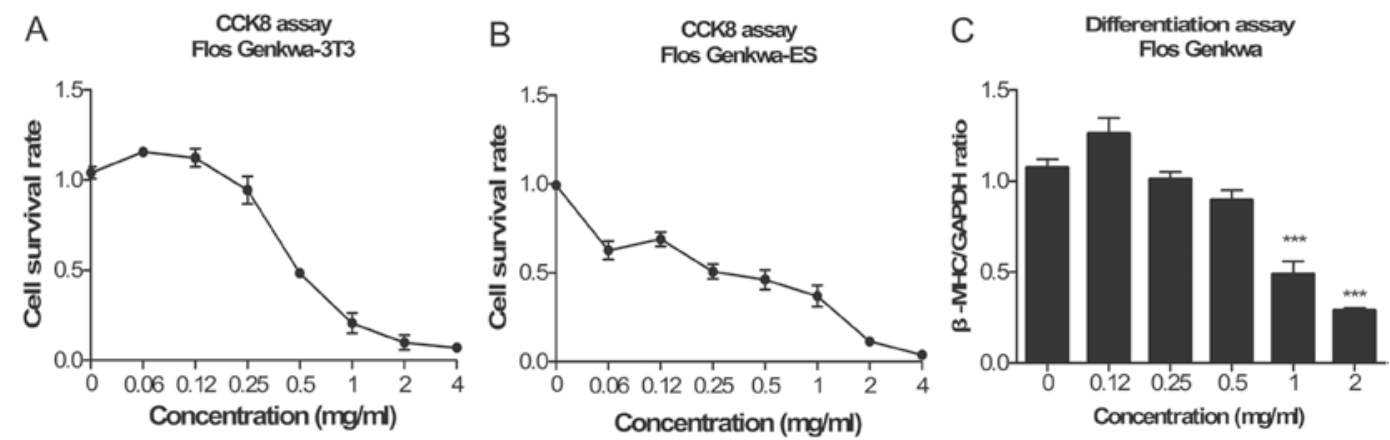

Figure 8. Embryonic stem cell (ESC) test for Flos Genkwa. Cytotoxicity assay with 3 T3 cells (A) and ESCs (B). Differentiation ESC assay (C). Relative levels of $\beta$-myosin heavy chain expression and cytotoxicity are represented as a percentage of the solvent control (control=100\%). Values are means \pm SEM $(\mathrm{n}=3)$. ${ }^{*} \mathrm{P}<0.05,{ }^{* *} \mathrm{P}<0.01,{ }^{* * *} \mathrm{P}<0.001$.

The $\mathrm{ID}_{50}$ value was $1.06 \mathrm{mg} / \mathrm{ml}$. The Coptis chinensis extract was defined as weakly embryotoxic.

Flos Genkwa. The $3 \mathrm{~T} 3$ cells and ESCs were both sensitive to Flos Genkwa. The $\mathrm{IC}_{50}$ values for the $3 \mathrm{~T} 3$ cells $(0.51 \mathrm{mg} / \mathrm{ml})$ and those for the ESCs $(0.75 \mathrm{mg} / \mathrm{ml})$ were below $1 \mathrm{mg} / \mathrm{ml}$ (Fig. 7A and B). The ESCs were slightly more sensitive than the $3 \mathrm{~T} 3$ cells when the concentration was under $0.25 \mathrm{mg} / \mathrm{ml}$. However, as the concentration was increased, the opposite trend was observed. The value of $\mathrm{ID}_{50}$ was $1.15 \mathrm{mg} / \mathrm{ml}$. Flos Genkwa was classified as strongly embryotoxic.

\section{Discussion}

The EST is an in vitro tool to assess the developmental toxic potency of test compounds in early development. Its coincidence rate is $78 \%$ compared with in vivo test results (21). The EST has been successfully used to classify the embryotoxicity of a large number of chemical compounds (25). It is now starting to be used to estimate the embryonic toxicity of natural compounds of Chinese medicinal herbs. Using the EST, bisphenol A and genistein were classified as weakly embryotoxic and strongly embryotoxic, respectively (23). Baicalin, an active constituent of Radix Scutellariae, demonstrated weak embryotoxicity based on the EST (24).

In the current study, we attempted to apply the EST to aqueous extracts of Chinese herbs. A mouse embryonic stem cell line, $\mathrm{OG}_{2}$, was used as a substitute for the D3 cell line in the EST, and the embryotoxicity of 5-FU, DPH and SAC was evaluated to verify the reliability of our findings. Our results revealed that 5-FU, DPH and SAC were strongly embryotoxic, weakly embryotoxic and non-embryotoxic, respectively, which is in accordance with the results of the EST validation test. This indicated that the findings were reliable when the $\mathrm{D}_{3}$ cell line was replaced with the $\mathrm{OG}_{2}$ cell line in the EST. We then used the EST to detect the embryotoxicity of the four selected tested Chinese herbal medicine aqueous extracts.

Rhizoma Atractylodes macrocephala is commonly used in TCM for pregnant women to treat abnormal fetal movement. In safety evaluation research, water-soluble extract of Rhizoma Atractylodes macrocephala revealed no genotoxicity based on four genotoxicity tests (26). Our in vitro results revealed that it exhibited no embryotoxicity.

Radix Isatidis is a valuable Chinese medicine with antibacterial and antiviral activities as well as an excellent safety profile (27). However, it was demonstrated that water boiled juice of Isatic tinctoria L caused micronuclei and sperm abnormalities in mice, and it was deemed a potential mutagen (28). Our results indicated that Radix Isatidis has no embryotoxicity.

A survey of Chinese herbal medicines used during pregnancy previously revealed that Coptis chinensis was one of the five most commonly used Chinese herbal medicines (4). It exhibited acute toxicity at $\mathrm{LD}_{50}$ under $10 \mathrm{~g} / \mathrm{kg}$ in mice (29). Berberine, one of the major constituents of Coptis chinensis, was also reported to exhibit genotoxicity (30). The present 
study suggests that Coptis chinensis has weak embryotoxic potential.

Since China's one-child family planning policy was enacted, Flos Genkwa has been widely used in abortion. No studies have investigated the embryonic toxicity of Flos Genkwa, although it is considered a toxic Chinese medicine. According to our results, Flos Genkwa was strongly embryotoxic.

In conclusion, the results of the present study suggest that extracts of Rhizoma Atractylodes macrocephala and Radix Isatidis are non-embryotoxic, whereas those of Coptis chinensis and Flos Genkwa are weakly embryotoxic and strongly embryotoxic, respectively. Our study potentially offers valuable information that may be used to expand the application of EST to the field of TCM. Moreover, as ESCs are pluripotent, herbal remedies with an ability to induce cell differentiation may be discovered. Such a finding would be of great significance in the field of TCM.

\section{Acknowledgements}

Thepresent study wasfunded by the GuangdongProvinceNatural Science Foundation of China (grant no. S2011010001898) and Guangdong Province Plan of Scientific and Technological Development (grant no. 2011B031700009). The authors would like to thank Professor Ma Zhiguo for expert assistance.

\section{References}

1. Lu F, Cao M, Wu B, et al: Urinary metabonomics study on toxicity biomarker discovery in rats treated with Xanthii Fructus. J Ethnopharmacol 149: 311-320, 2013.

2. Lu F, Gu Q, Wu R and Xu J: A structure-similarity-based software for the cardiovascular toxicity prediction of traditional Chinese medicine. Bioinformation 8: 110-113, 2012.

3. Zhang ZH, Zhao YY, Cheng XL, et al: General toxicity of Pinellia ternata (Thunb.) Berit. in rat: a metabonomic method for profiling of serum metabolic changes. J Ethnopharmacol 149: 303-310, 2013.

4. Chuang CH, Hsieh WS, Guo YL, et al: Chinese herbal medicines used in pregnancy: a population-based survey in Taiwan. Pharmacoepidemiol Drug Saf 16: 464-468, 2007.

5. Nordeng $\mathrm{H}$ and Havnen GC: Use of herbal drugs in pregnancy: a survey among 400 Norwegian women. Pharmacoepidemiol Drug Saf 13: 371-380, 2004.

6. Xu CL, Zhao YF, Shang XY and Niu WN: The effects of supplementing diets with Atractylodes macrocephala Koidz rhizomes on growth performance and immune function in piglets. J Animal Feed Sci 21: 302-312, 2012.

7. Jin C, Zhang PJ, Bao CQ, et al: Protective effects of Atractylodes macrocephala polysaccharide on liver ischemia-reperfusion injury and its possible mechanism in rats. Am J Chin Med 39: 489-502, 2011.

8. Zheng HZ, Dong ZH and Yu J: Modern Study of Traditional Chin Med J 328-334, 1997.

9. Xiao PG and Lian WY: The Illustrated Medicinal Plants of China. Shanghai Education Press, Shanghai, 1998.
10. Zhou BN: Some progress on the chemistry of natural bioactive terpenoids from Chinese medicinal plants. Mem Inst Oswaldo Cruz 86 (Suppl 2): 219-226, 1991.

11. Lee MY, Park BY, Kwon OK, et al: Anti-inflammatory activity of (-)-aptosimon isolated from Daphne genkwa in RAW264.7 cells. Int Immunopharmacol 9: 878-885, 2009.

12. Zhao Y, Yuan S, Li A, Zhang B and Wang Z: Effects of processing on toxicity and pharmacological action of Flos Genkwa. Zhongguo Zhong Yao Za Zhi 23: 344-347, 382-343, 1998 (In Chinese).

13. Hong JY, Chung HJ, Lee HJ, Park HJ and Lee SK: Growth inhibition of human lung cancer cells via down-regulation of epidermal growth factor receptor signaling by yuanhuadine, a daphnane diterpene from Daphne genkwa. J Nat Prod 74: 2102-2108, 2011.

14. Goel RK, Prabha T, Kumar MM, Dorababu M, Prakash and Singh G: Teratogenicity of Asparagus racemosus Willd. root, a herbal medicine. Indian J Exp Biol 44: 570-573, 2006.

15. Moallem SA, Ahmadi A, Moshafi $M$ and Taghavi MM: Teratogenic effects of HESA-A, a natural anticancer product from Iran, in mice. Hum Exp Toxicol 30: 851-859, 2011.

16. Chen CC and Chan WH: Impact effects of puerarin on mouse embryonic development. Reprod Toxicol 28: 530-535, 2009.

17. de Jong E, Barenys M, Hermsen SA, et al: Comparison of the mouse Embryonic Stem cell Test, the rat Whole Embryo Culture and the Zebrafish Embryotoxicity Test as alternative methods for developmental toxicity testing of six 1,2,4-triazoles. Toxicol Appl Pharmacol 253: 103-111,2011.

18. Spielmann $\mathrm{H}$ and Liebsch M: Lessons learned from validation of in vitro toxicity test: from failure to acceptance into regulatory practice. Toxicol In Vitro 15: 585-590, 2001.

19. Bremer S, Worth AP, Paparella M, et al: Establishment of an in vitro reporter gene assay for developmental cardiac toxicity. Toxicology In Vitro 15: 215-223, 2001.

20. Genschow E, Scholz G, Brown N, et al: Development of prediction models for three in vitro embryotoxicity tests in an ECVAM validation study. In Vitr Mol Toxicol 13: 51-66, 2000.

21. Whitlow S, Bürgin $\mathrm{H}$ and Clemann $\mathrm{N}$ : The embryonic stem cell test for the early selection of pharmaceutical compounds. ALTEX 24: 3-7, 2007

22. Paquette JA, Kumpf SW, Streck RD, Thomson JJ, Chapin RE and Stedman DB: Assessment of the Embryonic Stem Cell Test and application and use in the pharmaceutical industry. Birth Defects Res B Dev Reprod Toxicol 83: 104-111, 2008.

23. Kong D, Xing L, Liu R, et al: Individual and combined developmental toxicity assessment of bisphenol A and genistein using the embryonic stem cell test in vitro. Food Chem Toxicol 60: 497-505, 2013

24. Zhang W, Song DR, Wang YN and Zhu Z: Evaluation of embryotoxicity of baicalin based on embryonic stem cell test system. Chin J Pharmacol Toxicol 26: 864-869, 2012.

25. Spielmann $\mathrm{H}$ and Liebsch M: Validation successes: chemicals. Altern Lab Anim 30 Suppl 2: 33-40, 2002.

26. Zhao AS, Sun YL and Zhang LS: Safety assessment of Baizhu. Chin J Public Health 1: 43-45, 2006.

27. Wang HY, Ma YF and Zhou WY: On IRPS toxicity test and effects on immune system. Journal of Mianyang Normal University 31: 5, 2012.

28. Pang Z, Tang J, Zhu W and $\mathrm{Lu} \mathrm{Y:} \mathrm{Genetic} \mathrm{toxicity} \mathrm{of} \mathrm{water}$ boiled juice of Isatic Tinctoria L. in mice. Academic Journal of Guangzhou Medical College 28: 41-42, 2000.

29. Qiu SH, Tang WB, Li FY, Xiao JR and Chen BY: Experimental study of the acute toxicity on common-used bitter and cold medicines. Central South Pharmacy 2: 37-38, 2004.

30. Pasqual M, Lauer C and Moyna P and Henriques JA: Genotoxicity of isoquinoline alkaloid berberine in prokaryotic and eukaryotic organisms. Mutat Res 286 243-152, 1993. 